\title{
Interactive comment on "Homogenous regions based on extremogram for regional frequency analysis of extreme skew storm surges" by Marc Andreewsky et al.
}

\section{Anonymous Referee \#2}

Received and published: 17 July 2017

In the context of extreme storm surges, the authors adopt a methodology to define homogeneous regions in which observation follow - apart from a local normalization - the same probability distribution. The idea is that by studying the so-called regional frequency (in contrast to individual sites), uncertainty about the return levels of extreme events can be reduced. The methodology involves a set of statistical steps which are detailed in the manuscript. The authors study a considerable number of sites at the coasts of Great Britain, Atlantic coast of France, and part of the Atlantic coast of Spain. The obtained regions are compared to previous results by Weiss et al. Particular attention is given to the border effects and if so-called target sites are rather not at the border of the obtained regions.

Printer-friendly version

Discussion paper 
The manuscript is well structured, mostly comprehensive, and seems to be based on a careful analysis. However, in the present form I cannot recommend publication. It is not clear what the added value of the manuscript is. Online the discussion paper is posted as "Review article", but in my point of view it does not extensively "summarize the status of knowledge and outline future directions of research" (see also the rather small number of references). On the other hand, a "Research article" does also not seem to be justified since it does not "report substantial and original scientific results" - at least the addition to the existing literature appears to be minor to me. The authors mostly seem to perform a variation of the analysis previously done by Weiss et al.

Minor comments: - Figures are poor in style and quality - take more care about the paragraphs (ie 1 paragraph, 1 idea) - an alternative approach to the similarity of extreme events could be ROC-curves - what is I in Eq.(2)? - is it feasible to perform an out of sample validation? - auto-correlations can lead to the clustering of extreme events, see "Statistics of return intervals in long-term correlated records" Eichner, PRE, 2007 - sea-level exhibit long-term correlations, see "Evidence for long-term memory in sea level" Dangendorf, GRL, 2014; "Long-term sea level trends: natural or anthropogenic?" Becker, GRL, 2014 - temporal resolution of the data is not clear (different information in main text and appendix) - the usage of GPD "law" is misleading - appendix C is not clear

Interactive comment on Nat. Hazards Earth Syst. Sci. Discuss., https://doi.org/10.5194/nhess2016-378, 2017. 